\title{
FREE DIGITAL DISTANCE LEARNING FOR EMPLOYABILITY AND SOCIAL INCLUSION: THE PERCEPTIONS OF MIGRANTS LIVING ON THE MALTESE ISLANDS
}

\author{
Joseph Vancell, University of Hull, United Kingdom, Teemu Patala, ChangeLearning Alliance, \\ Finland, Alan Bruce, ChangeLearning Alliance, Ireland
}

\section{Introduction}

Asylum seekers are still moving, in great numbers, from Sub-Sahara Africa (SSA) and the Middle East to the European Union (EU) to seek protection from political oppression, war and poverty, as well as to reunite with family, and benefit from entrepreneurship and education (EC, 2017; EU, 2018). The UNHCR (2019) notes that 68.5 million people were forcibly displaced from their native countries. Mediterranean EU Member States are seeing an ever-growing influx of illegal migrants, through land and sea routes. During the first month of 2019, 6,727 migrants arrived in Europe, of which 5,685 were sea arrivals through Malta, Spain, Greece and Italy - the strategic entry points to the EU. In the previous year, Malta took 1,445 arrivals.

The issue of mass migration and population movement has dominated European discourse for at least 40 years. Since the invasion of Iraq and the various destabilization efforts against countries like Libya, Syria and Afghanistan, however, an entirely new phenomenon has erupted onto the centre stage - millions of people fleeing failed States, violence, terrorism and despair. Especially in the case of Syria (now in its fifth year of war) the problem of millions seeking to depart from the chaos has become huge. We are now entering a period of real transition however. Far from the malicious impact of war and violence, new problems arise around family fragmentation, emotional trauma, and the need to rebuild lives.

Maltese researchers indicate that these migrants stay in Malta for many months before being forcibly deported or given refugee status. Pisani (2012) also notes that there are also many migrants whose request for asylum is rejected and but cannot be deported because the countries they claim to come from (e.g. Somalia, Eritrea, Côte d'Ivoire, DRC) either pose a threat to migrants' safety or have no diplomatic relations with Malta. This renders enforcement of diplomatic relations very difficult (Pisani \& Giustiniani, 2009) and the "end result is experienced as a state of limbo: no chance of leaving the carceral archipelago of Malta and travelling to mainland Europe, and no real opportunity of return".

During their stay in Malta, asylum seekers, refugees and illegal migrants experience many difficulties, most notably "exploitation by unscrupulous employers who capitalize on the migrants' lack of choice in having to work" (English \& Mayo, 2019). They receive a pittance 
for their work, and do not enjoy the same rights as local or legal immigrant workers. They also have the threat of deportation constantly hanging over them. This precariousness is made more acute by immigrants' lack of basic education and employability skills, as well as social exclusion created mainly by lack of command of the local language and instances of racism, increased xenophobia and Islamophobia (Pisani, 2012) which run high in the Maltese islands. Indeed, although Malta's economy currently needs 35,000 new foreign workers to maintain its welfare state, owners of Maltese Small and Medium-Sized Enterprises (SMEs) prefer and employ Europeans and TCNs from India and Asian countries (including the Philippines) rather than the already available or incoming asylum seekers from African or Middle Eastern countries.

These desperate people have often survived traffickers, criminal gangs, corrupt police and other exploiters in their journey. The human cost of drowning, disruption, injury and deaths on land has only underlined the legal obligations of international law and treaties - the requirement for States to provide sanctuary and succour. This has not been done consistently. Although the warning signs were there, the scale and intensity of the refugee problem seemed to catch the European Union by surprise. The responses were uncoordinated, fragmented and often counter-productive. While many Member States were unprepared, others became actively antagonistic. Driven by a rising tide of xenophobia, they began to erect barriers not seen for decades in an effort to repulse often-desperate populations. Only one EU country articulated an initial policy of acceptance and welcome - Germany. For other countries in the front line the social and economic impact was significant with the burden falling particularly intensely on Greece, Italy and Malta.

Similar problems exist in the wider European context, where, as the official statistics show, more than $82 \%$ of asylum seekers are younger than 35 (Eurostat, 2018). This clearly indicates a demand for educational programmes for this group before they journey to Europe. This paper, based on the findings of a small qualitative research project, argues for free digital distance learning (FDDL) with the objective of enhancing employability, social inclusion and empowerment of potential adult refugees in European countries and, particularly, immigrants living in Malta, the smallest EU state but the country with the highest per capita number of illegal immigrants.

\section{The case for free digital distance learning for inclusion and employment}

The literature indicates that immigrants, travelling by land or sea, or both, to reach Europe, typically use smart technology and the Internet, in particular, smartphones and social media. They also use smart technology when in the host countries for seeking work and staying in contact with their families (Mason \& Buchmann, 2017). Despite this, various commentators agree that existing research offers limited insights into the process by which digital learning provision can contribute to the social inclusion of asylum seekers and refugees (Lewis \& Thacker, 2016; Castaño Muñoz, Colucci, \& Smith, 2018). Moreover, research shows that the 
use of digital learning, including MOOCs, by migrants and refugees is still very low (Liyanagunawardena, Adams, \& Williams, 2013; Glass, Shiokawa-Baklan, \& Saltarelli, 2016).

Colucci et al. (2017), in their review of available free digital learning (FDL) initiatives for migrants and refugees in Europe, note that the field of FDL for migrant/refugee learning and inclusion was developing rapidly and argued that, the scant research that exists indicates that

"MOOCs and other FDL offers (including free mobile learning) are effective and efficient ways of developing the skills needed by migrants and refugees for inclusion, civic integration, re-engagement in formal or non-formal education and employment."

However, the availability of cost-free dimension of these educational resources does not guarantee the migrants' participation in this type of learning. This is particularly true for potential migrants who are still living in their country of origin and those who are on their way to Europe. A number of papers and reports addressing migrants and their education indicate a number of pedagogic principles that must be integrated into an FDDL programme to ensure success.

English and Mayo (2019), banking on the work of many critical pedagogists, including Freire (1970), insist that Lifelong Learning (LLL) initiatives for migrants should not only prioritise skills and employability. The authors argue that
"Although the work factor weighs heavily on migrants' minds, the notion of citizenship ascribed to them would extend beyond that of being producers/consumers; hence, the education to be provided needs to help migrants obtain secure employment. This should be commensurate with their qualifications and life experiences, albeit more holistic to enable them to become critically active citizens with basic human rights."

English and Mayo (2019) also insist that any educational programme should treat migrants as assets to their current or potential host country instead of a burden. They argue that, in practice

\footnotetext{
"this would entail providing learning environments that treat migrants as active beings and not simply as passive consumers of knowledge being fed from above. It would engage their own strengths and cultures and build on them, taking into account their perspectives on things. It would allow them coownership of the programme through democratic participation and a dialogical approach through which all knowledge is at the centre of epistemological co-investigation. It would entail praxis or the means for all participants in the group setting, including the official educator, to be able to step back from their past and present environments to perceive them in a critical light."
} 
This would valorise the migrants' role of their labour in the smooth functioning of some of their host country's essential services, including the health and transport services and child and elderly care. This type of education can also "foster an understanding of the richness of the cultures that migrants bring with them" (English \& Mayo, 2019).

\section{Other key pedagogical features for successful FDDL}

In various studies about distance digital education (as, for example, compared to blended learning), self-directed learning and digital skills are considered to be very important for effective and meaningful participation. However, migrants and refugees may lack these skills. Moreover, their stressful situation might impede their learning (Castaño Muñoz, Colucci, \& Smidt, 2018). Mason \& Buchmann (2016) also make a case for an outreach plan with a strong support structures. Colucci et al. (2017) also indicate that migrants and refugees prefer approaches which are tailored to their specific needs and characteristics. These approaches are also in line with the UNHCR's recommendations for delivering education in crisis and conflict situations (UNHCR, 2019).

Another key pedagogical characteristic is the student-centred learning approach which is also personalised to the students' learning needs and preferences (Pane et al., 2017). Studies show that migrants and refugees are a more heterogeneous learning group than traditional adult learners. These studies indicate the importance of understanding the participants' learning demands and abilities (De Waard et al., 2014; Lewis \& Thacker, 2016). Obviously, migrants and refugees have unique needs and qualities that might affect their participation in any learning programme. This is true for face-to-face programmes and also digital learning initiatives which also come with their specific problems, including the lack of physical interaction that usually works against social presence.

Mason \& Buchmann (2016) identify many of the migrants' particular needs. These include their different backgrounds, their previous education, their location, their literacy level and language skills, whether their studies were interrupted, and any traumatic experiences they may have had. Moser-Mercer, Hayba, and Goldsmith (2016) and English and Mayo (2019) agree that human-centred initiatives are essential in fragile contexts and, ideally, learning must be designed following a bottom-up approach that involves the learners "as subjects and not objects" of the learning process (ibid.).

Moreover, Knowles (1973; p.45), through his andragogy model, argues that an adult has a "reservoir of knowledge that causes him (sic) to become an increasingly rich resource for learning, and at the same time provides him with a broadening base to which to relate new learning". It is therefore important for Knowles (1973) that FDDL initiatives are designed to engage migrants and refugees in collaborative learning activities in which every adult's experience is never devalued or ignored, otherwise the adult would not only perceive this as a rejection of his or her experience, but a rejection of him or her as a person. 
For the concept of digital learning that would be applied for FDDL a couple of case studies were identified. In 2009, Context Learning Finland (Finland's leading developer of digital learning content solutions) - and Amiedu (Finland's leading vocational adult education centre with 22,000 students) implemented a series of online training modules as part of the Immigrant Integration training program for immigrants to familiarize them with the Finnish employment system and working life (Amiedu, 2019). Organizations that have a central role in the Finnish employment system contributed to the project (e.g. Confederation of Finnish Construction Industries RT and The Federation of Finnish Enterprises) which was funded by The Ministry of Education. The online training was provided free of charge to immigrants who were either looking for employment in Finland or who had recently been employed in Finland. The training provided a highly practical and realistic approach to learning about working in Finland by using digital storytelling, case examples and video-based interactive exercises that let the learners engage with situations they are likely to face at work. Many of the challenges for immigrants when entering the Finnish working life deal with issues of language (in 2009 most employees still demand their employees to speak Finnish), Finnish culture, habits, legislation and "Finnishness" which is often related to introversion and other culture-specific communicational characteristics. Another aim of the program was to prepare students for a final test to achieve the "Working Life Certificate". It's an award to prove potential employers that the candidate has basic understanding about Finnish working life and knows the basic procedures regarding employment and working under contract.

Cultural Awareness in Technical and Industrial Vocational Training (CATIT) project, funded by the European Union's Leonardo da Vinci program in 2005-2007, developed an online program specializing in employment challenges in technical subject professions (training focused on the specific challenges identified with immigrants in technical and industrial professions of which many have to do with safety culture in work). The online program addressed these challenges by using animated case-based exercises which allow learners to experience working in the European context (Redecker et al., 2010).

\section{Methodology}

This qualitative study was based on a sample of 16 migrants who were either seeking asylum, whose request for asylum was rejected but could not be deported and were living in Malta for over a year, and refugees. To ensure that these participants are not harmed (in terms of the risk of job loss, discrimination and problems with government authorities), the anonymity of the participants was maintained throughout the whole project. Other ethical measures were taken, including ensuring that their right to interrupt their participation in the research was communicated to the participants. The average age of interviewed workers was 26 (14 male, 2 female).

\section{Findings}

The participants all came from Sub-Saharan African countries and were resident in Malta from 6 months to 4 years. They moved away from their country of origin to seek better 
economic opportunities, safety from war or both. Their intended final destination was a European country, but not Malta. They ended up in Malta by accident, not by choice. They all lived outside the detention centres in rented apartments with other migrants or refugees and paid their part of the rent from the money they gained through their job. They were all unskilled, had no educational qualifications, received only education comparable to Malta's primary education level, but all were literate and could speak English (although their proficiency in the language was weak yet comprehensible).

The migrants and refugees were all familiar with smart technology and the Internet. They all knew how to use their mobile phones for local and international calls as well for communicating with family and friends, in Malta, and in their native country, through social media. They were also using their smartphones, and in 2 cases, their laptops (which they bought in Malta and paid using money gained through their employment), for informal online learning through, for example, YouTube. Some used Facebook and/or WhatsApp so that they could discuss and learn, in collaboration with others, about such things as dealing with government officers, how to submit their asylum applications and clarify other formalities, including getting their residence permit, health insurance and accommodation. This also required the immigrants to communicate with different groups including local authorities, governmental offices, locals and volunteers.

Their preferred settlement was mainland Europe, and therefore, they preferred, if offered the opportunity, to learn more English, French, Italian or German, but not Maltese (the language of the Maltese Islands). Since English is Malta's other official language, during their stay in Malta, immigrants have various opportunities to learn the language. These include basic language courses offered by the Directorate of Lifelong Learning, and "ntegration courses" offered by various education agencies as part of the "Migrant Integration Strategy and Action Plan" (Ministry for European Affairs and Equality, 2017). Despite these opportunities none of the participants were, at the time of the interviews, following any of the courses on offer. They were also not participating in any training programmes, despite they had very low skills. They argued that they did not have the time to join face-to-face classes because their primary concerns were finding and keeping a good job (or jobs), and taking care of their family. Thus, the participants perceived e-learning through online means as a preferred option, even though none of the immigrants had participated in an online course.

A common thread in the interviews was that, as one participant put it, "countries of Europe know that there are (a) lot of problems in Africa" and should help people living in poverty or in dangerous environments by offering learning initiatives through the Internet. They argued that if given the opportunity, while still in their country of origin, to learn to enhance their employability, language proficiency and knowledge of a potential host country's traditions and customs, they would have participated eagerly in it. Some explained that deciding to move away from one's country, and saving enough money for the journey, took many months. For some it took years. During this period, they believed that they could have improved their knowledge of a specific European language, or mastered a skill through 
courses that were accessible in their country via online means. However, none of the participants knew of MOOCs (see for example, Colucci, Castaño Muñoz, \& Devaux, 2017) and learning resources that were already available, and were specifically designed to help prospective asylum seekers.

The participants also indicated that, given their low level of education and their weak foreign language skills, any digital learning initiative should present information in a simple and intuitive way, "just like phone apps" (participant 4). Preferably, it should also come with a strong support structure.

\section{Conclusion}

In general terms, education systems in Europe often do a poor job in providing opportunities for existing disadvantaged students, let alone vast numbers of new (and often traumatized) populations. The evidence of PISA research, for example, demonstrates a gap between rich and poor students in Europe which is significant and already growing before the refugee crisis emerged. The socio-economic crisis since 2008 exacerbated this. The reality is that education systems in most EU countries are not inclusive. Segregation is often seen by school type: students from disadvantaged backgrounds tend to be disproportionally in vocational secondary schools. In these the quality of schooling appears poorer and the resulting reading and mathematics skills are weaker. Immigrant children end up in poorer schools, usually vocational, and problems multiply into a systemic crisis of low expectations and inadequate outcomes.

Refugee children and youth need targeted support as they enter these already challenged school systems (such as intensive language and general induction programs to allow them to participate in mainstream classes as soon as possible). Some also present with war trauma, suggesting that schools need to offer psychological support. But beyond that, refugees will benefit from measures that make education systems more inclusive.

This study showed that FDDL can be a means of empowerment through knowledge and skills for employability - including language proficiency - and social inclusion. Many asylum seekers and refugees already learn informally through YouTube, Facebook and WhatsApp. FDDL initiatives give migrants more flexibility and accessibility to learning initiatives. However, despite the potential of e-learning for asylum seekers and refugees, the study identified significant challenges for the development and implementation of FDDL. This includes a lack of awareness of online educational offerings, particularly in the country of origin of the asylum seekers.

\section{References}

Amiedu (2019). Have you moved to Finland? Training and guidance for immigrants looking for employment in Finland. Retrieved 14 February, 2019, from https://www.amiedu.fi/inenglish/individual-customers/moved-to-finland/ 
Castaño Muñoz, J., Colucci, E., \& Smidt, H. (2018). Free Digital Learning for Inclusion of Migrants and Refugees in Europe: A Qualitative Analysis of Three Types of Learning Purposes. International Review of Research in Open and Distance Learning, 19(2), 1-21.

Colucci, E., Castaño Muñoz, J., \& Devaux, A. (2017). MOOCs and Free Digital Learning for the Inclusion of migrants and refugees: A European policy study. Proceedings of EMOOCs 2017: Work in Progress Papers of the Experience and Research Tracks and Position Papers of the Policy Track, 96-103. Retrieved from http://ceur-ws.org/Vol-1841/P02_114.pdf

Colucci, E., Smidt, H., Devaux, A., Vrasidas, C., Safarjalani, M., \& Castaño Muñoz, J (2017). Free Digital Learning Opportunities for Migrants and Refugees. An Analysis of Current Initiatives and Recommendations for their Further Use.

De Waard, I., Gallagher, M., Zelezny-Green, R., Czerniewicz, L., Downes, S., KukulskaHulme, A., \& Willems, J. (2014). Challenges for conceptualising EU MOOC for vulnerable learner groups. In U. Cress \& C. Delgado Kloos (Eds.), Proceedings of the second European MOOC Stakeholder Summit (pp. 33 - 42). Lausanne, Switzerland: EMOOCs.

Díaz Andrade, A., \& Doolin, B. (2016). Information and Communication Technology and the Social Inclusion of Refugees. MIS Quarterly, 40(2), 405-416.

English, L., \& Mayo, P. (2019). Lifelong learning challenges: Responding to migration and the Sustainable Development Goals. International Review of Education, 1.

Eurostat (2018). Asylum Statistics. Retrieved from https://ec.europa.eu/eurostat/statisticsexplained/index.php/Asylum_statistics\#Age_and_gender_of_first-time_applicants

Freire, P. (1970). Pedagogy of the Oppressed. New York: Continuum.

Gillespie, M., Ampofo, L., Cheesman, M., Faith, B., Iliadou, E., Issa, A., Osseiran, S., \& Skleparis, D. (2016). Towards effective digital provision for refugees. The Open University and France Medias Monde.

Glass, C. R., Shiokawa-Baklan, M. S., \& Saltarelli, A. J. (2016). Who takes MOOCs? New directions for Institutional Research, 167, 41-55.

Lewis, K., \& Thacker, S. (2016). ICT and the Education of Refugees: A Stocktaking of Innovative Approaches in the MENA Region. SABER-ICT Technical Paper Series; No. 17. World Bank, Washington, DC.

Liyanagunawardena, T. R., Adams, A. A., \& Williams, S. A. (2013). MOOCs: A systematic study of the published literature 2008-2012. The International Review of Research in Open and Distributed Learning, 14(3), 202-227.

Mason, B., \& Buchmann, D. (2017). ICT 4 Refugees. Deutsche Gesellschaft für Internationale Zusammenarbeit (GIZ) GmbH.

Ministry for European Affairs and Equality (2017). Integration = Belonging: Migrant Integration Strategy and Action Plan, Vision 2020. Malta. Retrieved from https://meae.gov.mt/en/Documents/migrant\%20integration-EN.pdf 
Moser-Mercer, B., Hayba, E. \& Goldsmith, J. (2016, May). Higher education spaces and protracted displacement: How learner-centered pedagogies and human-centered design can unleash refugee innovation. Paper presented at the UNESCO Chair Conference on Technologies for Development: From Innovation to Social Impact (Tech4Dev Conference). Lausanne, Switzerland 2-4 May 2016.

Pisani, M. (2012). Addressing the 'Citizenship Assumption' in Critical Pedagogy: Exploring the Case of Rejected Female Sub-Saharan African Asylum Seekers in Malta. Power and Education, 4(2), 185-195.

Pisani, M., \& Giustiniani, A (2009). Programmes and Strategies in Malta Fostering Assisted Return to and Reintegration in Third Countries. Valletta: EMN.

Redecker, C., Haché, A., \& Centeno, C. (2010). Using Information and Communication Technologies to promote Education and Employment Opportunities for Immigrants and Ethnic Minorities - POLICY BRIEF.

UNCHR (2019). Operational Portal: Refugees - Mediterranean Situation. Retrieved from https://data2.unhcr.org/en/situations/mediterranean 